\title{
Adoção de boas práticas agropecuárias em propriedades leiteiras da Região Sudeste do Brasil como um passo para a produção de leite seguro*
}

\author{
Good farming practices in dairy herds of Southeast Brazil as a step to approach food \\ safety at the farm level
}

\begin{abstract}
José Renaldi Feitosa Brito', Sandra Maria Pinto', Guilherme Nunes de Souza', Edna Froeder Arcuri', Maria Aparecida Vasconcelos Paiva Brito' \& Márcio Roberto Silva'
\end{abstract}

\section{RESUMO}

Bactérias patogênicas e resíduos de produtos químicos presentes no ambiente de produção podem contaminar o leite e causarem problemas tecnológicos e à saúde dos consumidores. Esforços para assegurar a qualidade e a segurança do leite e derivados devem ser iniciados na fazenda e para isso é necessária a adoção de boas práticas de produção, que são requisitos para o sistema APPCC (análise de perigos e pontos críticos de controle). O trabalho teve o objetivo de examinar e descrever o nível de adoção de boas práticas agropecuárias na produção de leite. Com ajuda de um questionário, entrevistas e registro fotográfico, foram avaliadas 48 propriedades leiteiras localizadas nos Estados de Minas Gerais e Rio de Janeiro. Havia predominância de gado mestiço Holandês-Zebu (34/48; 71\%), seguido por animais da raça Holandesa (19\%), Jersey (8\%) e Pardo-Suíça (2\%). A média de produção de leite dos rebanhos era de $686 \pm 403 \mathrm{~kg} /$ dia, e o número médio de vacas em lactação era $65 \pm 42$. Em duas propriedades as vacas em lactação eram mantidas em confinamento total (sistema “free stall") e nas demais se adotava o sistema extensivo, a pasto. Os resultados obtidos indicam que grande parte das propriedades adotava as principais práticas consideradas necessárias para a produção de leite de qualidade. Contudo, foram identificados vários pontos que deveriam receber maior atenção para capacitar os produtores a adotarem um programa de boas práticas. Esses incluem: manejo das bezerras na fase de recria; armazenamento dos alimentos; realização de testes para o controle da tuberculose; monitoração e controle da mastite, incluindo a antissepsia de tetos e o tratamento da vaca seca; uso desnecessário de anti-helmínticos em vacas em lactação; uso indiscriminado de carrapaticidas em razão da não-adoção de um programa estratégico de controle de carrapatos; não-obediência ao período de carência para antibióticos usados na vaca em lactação; higienização inadequada dos equipamentos de ordenha e de estocagem do leite, assim como o dimensionamento inadequado destes últimos.

Descritores: APPCC, mastite, qualidade do leite, segurança alimentar.

\begin{abstract}
Pathogenic bacteria and chemical residues found in the farm environment can contaminate raw milk. This may result in technological problems and pose a risk to the consumers. Efforts to ensure quality and safety of milk should consider primarily the dairy farm, through the adoption of good agricultural practices (GAP), which are needed for the implementation of HACCP systems (hazard analysis critical control points). The objective of the work was to describe the level of adoption of GAP by milk producers. A survey was conducted on 48 dairy farms located in the States of Minas Gerais and Rio de Janeiro, in Southeast Brazil. The survey included questionnaires, personal interviews with farm managers photographic registration. In about two thirds of the farms (71\%) the herds were formed by crossbred cows (Holstein $\mathrm{x}$ Zebu), followed by Holstein (19\%), Jersey (8\%) and Brown-Swiss cows (2\%). The daily average milk production was $686 \pm$ $403 \mathrm{~kg}$ and the average number of lactating cows was $65 \pm 42$. In two farms lactating cows were kept on free stalls. In the remaining farms they were kept on pasture most of the time. Most of the recommended procedures for milk production were followed. However, it was identified several procedures that the milk producers should pay more attention, because of their interferences with milk quality and food safety. These procedures were: calf management after weaning, food storage, tuberculosis control, mastitis control and monitoring, including teat disinfection and dry cow therapy; unnecessary use of anthelmintics in lactating cows, ticks treatment of lactating cows, absence of a plan to discard milk after antibiotic use in lactating cows, milking parlor and milking equipment sanitization, and size adequacy of the storage milk tank.
\end{abstract}

Key words: food safety, HACCP, mastitis, milk quality. 


\section{INTRODUÇÃO}

Vários patógenos podem contaminar o leite e causarem doenças ao homem, particularmente se o leite é consumido cru ou na forma de derivados $[3,9]$. O leite pode, ainda, carrear contaminantes e resíduos químicos como antibióticos e micotoxinas (aflatoxinas) [2], que constituem risco para a saúde pública, porque em geral não são eliminados pelo tratamento térmico usado na indústria.

Esforços para garantir a qualidade e a segurança do leite têm sido recomendados [7,15]. Programas como as boas práticas e o APPCC (análise de perigos e pontos críticos de controle) vêm sendo implementados na produção de alimentos, com destaque para o segmento da indústria [16]. Existem dificuldades para implementação do sistema APPCC em fazendas leiteiras [16,17,24], mas exemplos do seu emprego visando à melhoria da produção ou ao controle de doenças, como a mastite, são encontrados na literatura [5,6,13,17,20,21,23].

As normas para implementação do sistema APPCC são definidas no Codex Alimentarius [10]. São previstos 12 passos, sendo um deles a elaboração de fluxogramas, específicos para cada caso. Esses contribuem para melhorar o controle das técnicas utilizadas no manejo dos animais e equipamentos, e permitem identificar potenciais problemas, assim como a necessidade de treinamentos [8].

Esse trabalho teve o objetivo de detalhar e examinar a adoção de procedimentos, componentes das boas práticas agropecuárias, como requisito para a implementação do sistema APPCC em propriedades leiteiras do Sudeste brasileiro. Considerando-se a diversidade de manejos, procurou-se avaliar, também, se o grau de tecnologia adotado na ordenha poderia ser um diferencial para a adoção de boas práticas.

\section{MATERIAIS E MÉTODOS}

O estudo foi conduzido em 48 propriedades leiteiras da Zona da Mata de Minas Gerais e Região Norte do Estado do Rio de Janeiro, selecionadas com base no histórico da contagem de células somáticas, adoção de ordenha mecanizada e refrigeração do leite na propriedade. Dados abrangendo o manejo geral do rebanho, com enfoque nos aspectos de biossegurança, conservação dos alimentos, manejo higiênico-sanitário, obtenção e armazenamento do leite e tratamento de doenças foram obtidos com o auxílio de questionário, complementado por observações diretas e registro fotográfico. Foram elaborados fluxogramas dos procedimentos gerais de ordenha e armazenamento de leite de cada propriedade, tendo como princípio orientador a adoção de boas práticas agropecuárias [11], visando à elaboração de um fluxograma padrão. A elaboração, teste e aplicação dos questionários e o desenho dos fluxogramas de produção foram realizados de acordo com Noordhuizen et al. [23].

Para avaliar se o grau de tecnologias adotadas constituía um diferencial para a adoção de boas práticas, as propriedades foram divididas em dois grupos, conforme o tipo de equipamento de ordenha usado (balde ao pé versus circuito fechado). Para verificar a influência do tamanho do rebanho em relação às subdivisões de animais na fase de recria, foram realizadas as análises de Qui-quadrado, correlação de Pearson e a equação linear, usando a fórmula $\mathrm{y}=\mathrm{a}+\mathrm{bx}[28]$.

\section{RESULTADOS}

\section{Caracterização dos rebanhos}

Nas 48 propriedades predominou o gado mestiço Holandês-Zebu (34/48; 71\%). Os demais rebanhos (29\%) eram constituídos de animais da raça Holandesa (19\%), Jersey (8\%) e Pardo-Suíça (2\%). A média de produção de leite dos rebanhos era de $686 \pm 403 \mathrm{~kg} / \mathrm{dia}$, e o número médio de vacas em lactação era $65 \pm 42$. Em duas propriedades as vacas em lactação eram mantidas em confinamento total (sistema "free stall"); nas demais se adotava o sistema extensivo, a pasto. As vacas recebiam suplementação alimentar no período da seca, entre os meses de maio a setembro, aproximadamente, sendo mantidas durante a maior parte do dia em currais próximo à sala de ordenha. Em 41 (85\%) propriedades as condições de armazenamento e de fornecimento dos alimentos aos animais eram adequadas, considerando-se a ausência de umidade e de mofos, que seriam um indicativo de presença de micotoxinas.

Todas as propriedades dispunham de locais específicos para vacas em lactação. Em $90 \%$ das propriedades havia local separado para as vacas secas. Em 79\% delas, as vacas eram conduzidas para baias, piquetes ou pastos específicos, entre 15 a 30 dias antes do parto. 
O colostro era fornecido aos recém-nascidos imediatamente após o parto em todas as propriedades. Em metade delas, as bezerras eram mantidas em abrigos individuais e em bezerreiros coletivos na outra metade. Diferenças marcantes de manejo foram observadas na forma de separar lotes de bezerras na fase de recria. O agrupamento de bezerras após o desmame variou desde a manutenção de um (38\% dos casos) e de dois (29\%) até o máximo de sete lotes em uma única (2\%) propriedade (Tabela 1). Examinou-se a possibilidade de o número de lotes estar relacionado ao tamanho dos rebanhos, mas não houve influência do número de subdivisões na recria em função do número de vacas em lactação ( $p>0,05)$, sendo esses dados corroborados pela correlação de Pearson, não significativa, $(\mathrm{p}=0,41)$ e pela equação linear $\left(\mathrm{R}^{2}=0,015\right)$.

Tabela 1. Formação de lotes de recria de bezerras em 48 propriedades leiteiras em relação ao número de vacas em lactação.

\begin{tabular}{cccc}
\hline \multirow{2}{*}{$\begin{array}{c}\text { Subdivisões } \\
\text { para recria }\end{array}$} & \multicolumn{2}{c}{ Propriedades } & $\begin{array}{c}\text { No. médio de } \\
\text { vacas em lactação }\end{array}$ \\
\cline { 2 - 4 } & № & $\%$ & \\
\hline 1 & 18 & 38 & $60 \pm 34$ \\
2 & 14 & 29 & $59 \pm 31$ \\
$>2^{*}$ & 16 & 33 & $75 \pm 55$ \\
Total & 48 & 100 & $65 \pm 41$ \\
\hline *9 propriedades com 3; 5 com 4; 1 com 5 e 1 com 7 subdivisões
\end{tabular}

\section{Manejo sanitário e aspectos de biossegurança}

Todos os rebanhos adotavam um programa de vacinação. As vacinas eram usadas contra as seguintes doenças: febre aftosa (100\% dos rebanhos), brucelose (96\%), carbúnculo sintomático (98\%) e raiva $(98 \%)$. Exames regulares para brucelose e tuberculose eram realizados em $81 \%$ e $71 \%$ dos rebanhos, respectivamente. Em 34 rebanhos $(71 \%)$ as vacas doentes eram mantidas separadas das vacas sadias. O monitoramento da mastite clínica (teste da caneca) e da mastite subclínica ("California mastitis test") era realizado em $80 \%$ e $60 \%$ dos rebanhos, respectivamente. Em 27 rebanhos (56\%) era realizado o tratamento das vacas no momento da secagem. O uso de carrapaticidas e de anti-helmínticos em vacas em lactação foi observado em $94 \%$ e $56 \%$ dos rebanhos, respectivamente. Em 18 rebanhos (37,5\%) constatouse a possibilidade de risco de presença de resíduos de antimicrobianos no leite, em razão da não obediência ao prazo de carência e descarte do leite somente do quarto mamário tratado.

\section{Manejo da ordenha}

A sequiência e o percentual de adoção de procedimentos recomendados para a ordenha e armazenamento do leite são apresentados na Figura 1. Vinte e sete das 48 propriedades $(56 \%)$ possuíam ordenhadeira do tipo circuito fechado e as demais (44\%) adotavam o modelo balde ao pé. Esses dois grupos foram comparados para avaliar se o sistema de ordenha era associado com a adoção de boas práticas na propriedade. Os resultados obtidos são apresentados na Tabela 2, onde se pode verificar que nos rebanhos que adotavam o modelo balde ao pé havia deficiências mais acentuadas em relação à higienização da ordenhadeira, aos hábitos higiênicos dos ordenhadores e à filtragem do leite.

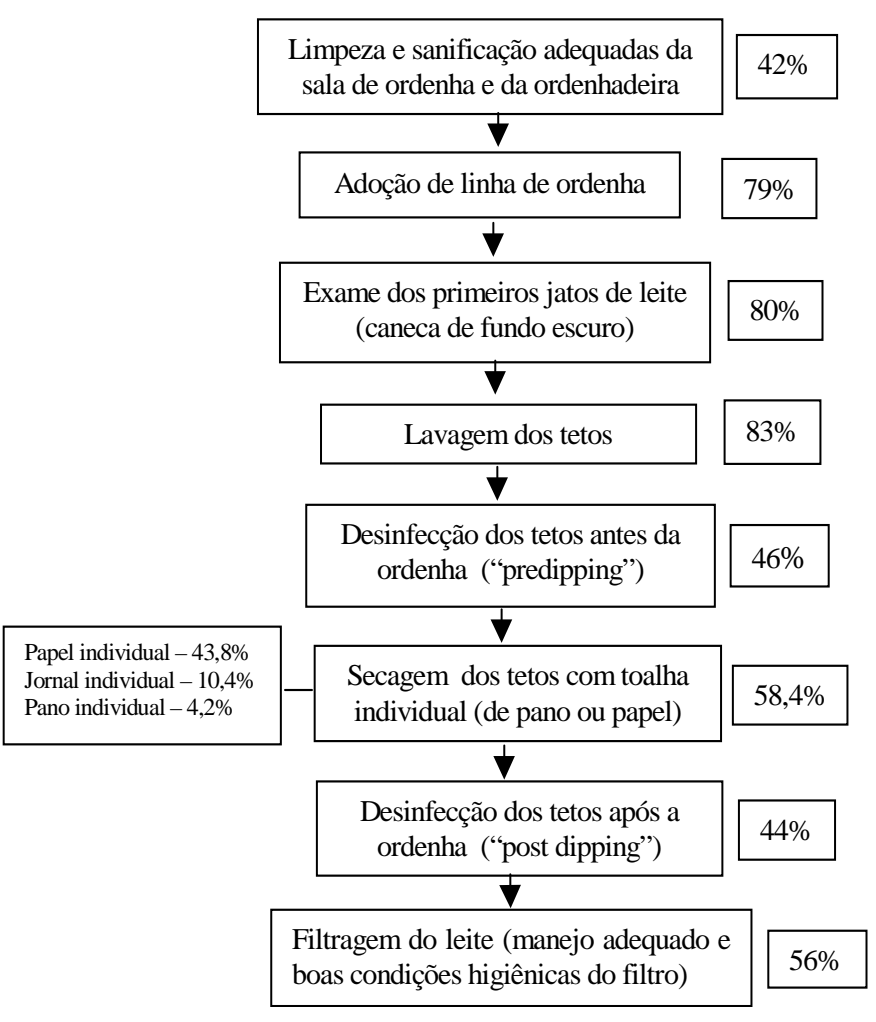

Figura 1. Seqüência e freqüência $(\%)$ de adoção de procedimentos componentes das Boas Práticas Agropecuárias, durante e após a ordenha, em 48 propriedades bovinas leiteiras da Região Sudeste. 
Tabela 2. Porcentual de adoção de procedimentos considerados adequados durante e após a ordenha em 48 propriedades leiteiras, de acordo com o sistema de equipamento de ordenha

\begin{tabular}{|c|c|c|c|}
\hline \multirow{2}{*}{ Procedimentos } & \multicolumn{2}{|c|}{ Tipo de Ordenhadeira } & \multirow{2}{*}{$\begin{array}{c}\text { Nível de } \\
\text { significância }\end{array}$} \\
\hline & Circuito fechado & Balde ao pé & \\
\hline Limpeza e sanificação da sala de ordenha & $13(48 \%)$ & $7(33 \%)$ & n.s. ${ }^{*}$ \\
\hline Limpeza e sanificação da ordenhadeira & $16(60 \%)$ & $5(24 \%)$ & $p<0,05$ \\
\hline Adoção da linha de ordenha & $20(74 \%)$ & $18(86 \%)$ & n.s. \\
\hline Exame dos primeiros jatos de leite & $24(86 \%)$ & $15(72 \%)$ & n.s. \\
\hline Lavagem dos tetos & $23(85 \%)$ & $17(81 \%)$ & n.s. \\
\hline Desinfecção dos tetos antes da ordenha & $15(56 \%)$ & $7(33 \%)$ & n.s. \\
\hline Secagem dos tetos antes da ordenha & $20(74 \%)$ & $10(48 \%)$ & n.s. \\
\hline Hábitos higiênicos dos ordenhadores & $24(89 \%)$ & $11(52 \%)$ & $p<0,05$ \\
\hline Desinfecção dos tetos após a ordenha & $14(52 \%)$ & $7(33 \%)$ & n.s. \\
\hline Filtragem do leite & $19(70 \%)$ & $8(38 \%)$ & $p<0,05$ \\
\hline Temperatura do tanque de refrigeração $(£ 4 \stackrel{\circ}{ } \mathrm{C})$ & $17(63 \%)$ & $17(81 \%)$ & n.s. \\
\hline Limpeza e sanificação do tanque de refrigeração do leite & $9(33 \%)$ & $6(29 \%)$ & n.s. \\
\hline Total de rebanhos & 27 & 21 & \\
\hline
\end{tabular}

\section{Armazenamento do leite}

Em 47 das 48 propriedades o leite era refrigerado imediatamente após a ordenha, em tanques de expansão, cuja capacidade variou entre 300 e 6.000 litros. Contudo, somente em 34 propriedades (71\%), o leite atingia a temperatura desejável, inferior ou igual a $4^{\circ} \mathrm{C}$, até o momento em que era transportado para a indústria. Os problemas relacionados ao armazenamento do leite foram de dois tipos: procedimentos de limpeza (Tabela 2) e inadequação do tamanho do tanque de refrigeração em relação à produção de leite (Tabela 3). Em somente $52 \%, 27 \%$ e $23 \%$ das propriedades eram utilizados de forma rotineira e adequada, detergente alcalino, detergente ácido e sanitizante, respectivamente. A filtragem do leite era realizada de maneira adequada em 27 (56\%) propriedades.

\section{DISCUSSÃO}

Neste trabalho, foram identificados e quantificados vários procedimentos recomendados para a produção de leite, que são incluídos nos manuais de "boas práticas de produção" [11]. Entretanto, alguns procedimentos, adotados de forma inadequada em alguns rebanhos, ou ignorados, poderiam resultar em risco para a saúde do consumidor. Dentre esses, podem ser citados os perigos químicos, representados pelo
Tabela 3. Avaliação do dimensionamento dos tanques de refrigeração de leite, considerando-se o volume produzido e estocado por 48 horas em 48 propriedades da Região Sudeste.

\begin{tabular}{lcc}
\hline $\begin{array}{c}\text { Dimensionamento do } \\
\text { tanque }\end{array}$ & Propriedades \\
\cline { 3 - 3 } de refrigeração do leite & Número & $\%$ \\
\hline $\begin{array}{c}\text { Subdimensionado (menor } \\
\text { ou exatamente igual à } \\
\text { produção) }\end{array}$ & 15 & 31 \\
$\begin{array}{c}\text { Dimensão adequada* } \\
\begin{array}{c}\text { Superdimensionado (>4 } \\
\text { vezes o volume de } \\
\text { produção) } \\
\text { Total }\end{array}\end{array}$ & 13 & 27 \\
\hline
\end{tabular}

*considerando até quatro vezes o volume de leite produzido em um dia.

emprego disseminado de carrapaticidas e antihelmínticos para vacas em lactação, o uso de antimicrobianos no tratamento da mastite, sem obediência ao período de carência, e, em menor número de rebanhos, a possibilidade de contaminação da ração animal com micotoxinas.

A avaliação das condições de higiene da sala de ordenha e da ordenhadeira mecânica indicou que os procedimentos de higienização eram realizados de forma inadequada em muitas propriedades, especialmente em relação ao emprego de detergentes indicados e a frequiência de uso. Essas falhas podem explicar em parte as altas contagens de bactérias encon- 
tradas em muitos rebanhos $[18,27]$ e a reduzida vida de prateleira do leite e derivados lácteos, além de influenciar a saúde da vaca em lactação [14,15].

Alguns procedimentos que eram esperados ser parte da rotina de rebanhos do padrão dos escolhidos para o estudo foram, surpreendentemente, ausentes em grande número deles. Esses procedimentos incluem a secagem adequada de tetos antes da ordenha e o tratamento com antibiótico no início do período seco $[1,22]$. Tais procedimentos são adotados na maioria dos rebanhos de países de pecuária leiteira desenvolvida [30], o que contribuiu para o controle das infecções subclínicas e a redução da contagem de células somáticas no leite dos rebanhos desses países.

A freqüência de adoção do exame dos primeiros jatos de leite antes da ordenha foi verificada em $80 \%$ dos rebanhos estudados, uma freqüência similar à observada em rebanhos leiteiros dos Estados Unidos [30], indicando que esse procedimento está incorporado à rotina dos rebanhos da região. Entretanto, observou-se baixa freqüência de adoção em relação à ordenha de tetos limpos e secos e de aplicação de desinfetantes ao final da ordenha. Estudos conduzidos nos últimos 25 anos comprovaram a influência benéfica desses procedimentos, tanto para prevenir a contaminação do leite, quanto para a redução da mastite $[15,27,29]$.

A lavagem dos tetos era realizada na maioria das propriedades. Entretanto, a antissepsia dos tetos antes e após a ordenha foi verificada em poucas propriedades. Tais práticas, quando realizadas adequadamente poderão prevenir ou reduzir a incidência de mastite e conseqüentemente melhorar a qualidade do leite $[4,19,25]$.

A prática de secagem dos tetos, apesar de realizada na maioria das propriedades, era feita de forma inadequada em muitas delas, como a utilização de pano comum a todos os animais, o que pode resultar em aumento da contaminação bacteriana do leite como apontado por vários autores [12,26].
$\mathrm{O}$ armazenamento e refrigeração do leite na fazenda é um dos pontos críticos relacionados no sistema APPCC [15], sendo recomendada a temperatura abaixo de $4{ }^{\circ} \mathrm{C}$. Observou-se que, além de muitas propriedades não refrigerarem o leite na temperatura ideal, algumas possuíam tanques superdimensionados, o que poderia resultar em eventual congelamento e alterações no leite, quando o volume armazenado fosse pequeno. Em outras propriedades verificou-se o oposto, com tanques insuficientes para armazenar o leite. Esses dados indicam falhas de planejamento ou de orientação adequada na adoção de tecnologias. Essas falhas podem ser responsáveis por prejuízos econômicos e redução da qualidade do leite.

\section{CONCLUSÕES}

Os resultados obtidos deste trabalho indicam que grande parte das propriedades estudadas adotam as principais práticas consideradas necessárias para a produção de leite de qualidade. Entretanto, uma série de procedimentos que não são adotados em muitas delas podem colocar em risco tanto a qualidade do leite para processamento quanto a saúde do consumidor. Os principais pontos que merecem atenção por parte dos produtores e da Assistência Técnica e Extensão Rural, e que deveriam ser incluídos em um programa de boas práticas são os seguintes:

- manejo adequado das bezerras na fase de recria;

- correto armazenamento dos alimentos;

- realização de testes para o controle da tuberculose;

- monitoração e controle da mastite, incluindo a

- antissepsia de tetos e o tratamento da vaca seca;

- não-uso de anti-helmínticos em vacas em lactação;

- uso adequado de carrapaticidas, com adoção de um

- programa estratégico de controle;

- obediência ao período de carência para antibióticos

- usados na vaca em lactação;

- higienização adequada dos equipamentos de ordenha e de estocagem do leite, assim como o dimensionamento adequado destes últimos.

\section{REFERÊNCIAS}

1 Berry E. A. \& Hillerton J. E. 2002. The effect of selective dry cow treatment on new intramammary infections. Journal of Dairy Science. 85:112-121.

2 Blüthgen A. 2000. Contamination of milk from feed. Bulletin of the International Dairy Federation. 356: 43-47.

3 Boor K. J. 1997. Pathogenic microorganisms of concern to the dairy industry. Dairy, Food and Environmental Sanitation. 17:714-717. 
Brito J.R.F., Pinto S.M., Souza G.N., Arcuri E.F., Brito M.A.V.P. \& Silva M.R. 2004. Adoção de boas práticas agropecuárias em propriedades leiteiras da Região Sudeste do Brasil como um passo para a produção... Acta Scientiae Veterinariae. 32: $125-131$.

4 Brito J. R. F., Brito M. A. V. P. \& Verneque R. S. 2000. Contagem bacteriana na superfície de tetas de vacas submetidas a diferentes processos de higienização, incluindo a ordenha manual com participação do bezerro para estimular a descida do leite. Ciência Rural. 30: 847-850.

5 Cullor J. S. 1995. Implementing the HACCP program on your clients' dairies. Veterinary Medicine. 90: $290-295$.

6 Cullor J. S. 1997. HACCP (Hazard analysis critical control points): is it coming to the dairy? Journal of Dairy Science. 80:3449-3452.

7 Daly P. 1998. Food safety and quality assurance systems at farm level. Farm \& Food. 8: 18-20.

8 Day D. J., Nelson A., Cnossem S. \& Cullor J. 1999. Consultants view of dairy breakthrough management. In: Proceedings of the 38th National Mastitis Council Annual Meeting (Arlington, USA). pp.34-37.

9 Donnelly C. W. 1990. Concerns of microbial pathogens in association with dairy foods. Journal of Dairy Science. 73 : 1656-1661.

10 FAO. 1999. Codex Alimentarius Comission/WHO. Proposed draft code of hygienic practice for milk and milk products (at step 3 of the procedure). In: Proceedings of the Joint FAO/WHO Standards Programme. Codex Committee on Food Hygiene. v.32. (Washington, USA). 13 p.

11 FAO. 2002. Good agricultural practices. 2nd edn. Rome: FAO, 6 p.

12 Galton D. M., Petersson L. G. \& Merrill W. G. 1986. Effects of premilking udder preparation practices on bacterial counts in milk and on teats. Journal of Dairy Science. 69: 260-266.

13 Gibbons-Burgener S. N., Kaneene J. B., Lloyd J. W. \& Erskine R. J. 2000. Influence of the milk and dairy beef quality assurance program on dairy farm drug management practices. Journal of the American Veterinary Medical Association. 216: 1960-1964.

14 Hamann J. \& Krömker V. 1997. Potential of specific milk composition variables for cow health management. Livestock Production Science. 48: 201-208.

15 Heeschen W. H., Reichmuth J. \& Suhren G. 1997. Quality milk production - potential hazards, critical control points and application of risk analysis. In: Proceedings of the 36th National Mastitis Council Annual Meeting (Albuquerque, USA). pp. 4-18.

16 Heggum C. 2001. Trends in hygiene management - the dairy sector example. Food control. 12: 241- 246.

17 Heuchel V., Parguel P., David V., Lenormand M. \& Le Mens P. 1999. Maîtrise de la qualité hygiénique laitière: l'application du HACCP en élevage. In: Rencontres autour des recherches sur les ruminants - 6, Paris - INRA . 6: 291297.

18 Johnson A. P. 2000. A proper milking routine: The key to quality milk. In: Proceedings of the 39th National Mastitis Council Annual Meeting (Atlanta, USA). pp. 123-126.

19 Leslie K. E., Kelton D. F., Edge V. L., Wagter L. C., Day K. J. \& Godkin M.A. 2000. Milking management in Ontario Dairy Herds and relationship to milk quality. In: Proceedings of the 39th National Mastitis Council Annual Meeting (Atlanta, USA). pp.111-122.

20 Milk \& Dairy Beef Quality Assurance Program. 1998. Milk and dairy beef residue prevention protocol: 1997-1998. Producer manual. [s.1.], 70 p.

21 Nagel S. \& Reneau J. K. 2001. Dairy farm HACCP: PMO bulk tank temperature and wash cycle compliance on ten Minnesota dairies. In: Proceedings of the 40th National Mastitis Council Annual Meeting (Reno, USA). pp. $258-259$.

22 Neave F. K., Dodd F. H. \& Kingwell R. G. 1966. A method of controlling udder disease. Veterinary Record. 78: 521-523,

23 Noordhuizen J. P. T. M., Frankena K., Hoofd C. M. Van Der \& Graat E. A. M. (Eds). 1997. Application of quantitative methods in Veterinary Epidemiology. Wageningen: Wageningen Pers, 445 p.

24 Panisello P. J., Quantick P. C. \& Knowles M. J. 1999. Towards the implementation of HACCP: results of a UK regional survey. Food control. 10: 87-98.

25 Pankey J. W., Wildman P. A., Drechsler P. A. \& Hogan J. S. 1987. Field trial evaluation of premilking teat disinfection. Journal of Dairy Science. 70: 867-872.

26 Rasmussen M. D. 2000. A review of milking preparation. The science. In: Proceedings of the 39th National Mastitis Council Annual Meeting (Atlanta, USA). pp. 104-110.

27 Rasmussen M. D., Bjerring M., Justesen P. \& Jepsen L. 2002. Milk quality on Danish farms with automatic milking systems. Journal of Dairy Science. 85: 2869-2878. 
Brito J.R.F., Pinto S.M., Souza G.N., Arcuri E.F., Brito M.A.V.P. \& Silva M.R. 2004. Adoção de boas práticas agropecuárias em propriedades leiteiras da Região Sudeste do Brasil como um passo para a produção... Acta Scientiae Veterinariae. 32: $125-131$.

28 Sampaio I. B. M. 2002. Estatística aplicada à experimentação animal. 2.ed. Belo Horizonte: Fundação de Ensino e Pesquisa em Medicina Veterinária e Zootecnia, 265 p.

29 Slaghuis B. 1996. Sources and significance of contaminants on different levels of raw milk production. In: Proceedings of the IDF Symposium on bacteriological quality of raw milk. Wolfpassing: IDF, pp. 19-27.

30 USDA. 2002. Part III: Reference of dairy cattle health and health management practices in the United States. USDA/ APHIS/VS/CEAH, National Animal Health Monitoring System, Fort Collins, CO. \#N400.1203. 